\title{
UTILIZAÇÃO DE RESÍDUOS DA CADEIA PRODUTIVA DO PINHÃO PARA A PRODUÇÃO DE PELLETS PARA GERAÇÃO DE ENERGIA
}

\author{
Rodolfo Cardoso Jacinto ${ }^{1}$, Martha Andreia Brand ${ }^{2 *}$, Alexsandro Bayestorff da Cunha ${ }^{2}$, Daniele Lourenço \\ Souza $^{3}$, Murilo Vieira da Silva ${ }^{3}$ \\ ${ }^{1}$ Universidade do Estado de Santa Catarina, Curso de Mestrado em Engenharia Florestal, Lages, Santa Catarina, Brasil - \\ rodolfocja@gmail.com \\ ${ }^{2}$ Universidade do Estado de Santa Catarina, Departamento de Engenharia Florestal, Lages, Santa Catarina, Brasil - martha.brand@udesc.br*, \\ alexsandro.cunha@udesc.br \\ ${ }^{3}$ Universidade do Estado de Santa Catarina, Curso de Engenharia Florestal, Lages, Santa Catarina, Brasil - \\ danielelourencosouza@gmail.com, muriloenf.vieira@gmail.com
}

Recebido para publicação: 28/04/2017 - Aceito para publicação: 20/08/2017

\begin{abstract}
Resumo
Este trabalho teve como objetivo analisar a qualidade dos pellets produzidos a partir de diferentes misturas contendo madeira de Pinus e falhas de pinhão, com base nos critérios de qualidade da norma ISO 17225-2. Os materiais analisados in natura e utilizados para a produção dos pellets foram as escamas estéreis e não fertilizadas (falhas de pinhão) dos estróbilos femininos de Araucaria angustifolia, e a maravalha de Pinus spp. Os pellets foram compostos por: $100 \%$ de falha de pinhão (F100); $75 \%$ de falha e $25 \%$ de Pinus (F75P25); 50\% de cada tipo de biomassa (F50P50); 25\% de falha e 75\% de Pinus (F25P75) e 100\% de Pinus (P100). Foram analisadas as propriedades físicas, químicas e energéticas da biomassa in natura e as propriedades físicas, mecânicas e energéticas dos pellets produzidos com as misturas de biomassa. Os pellets foram classificados segundo as categorias de qualidade da norma ISO 17225-2. Os resultados demonstraram que as variações nas propriedades da biomassa in natura influenciam na qualidade dos pellets. A inclusão do Pinus reduziu a densidade a granel das misturas antes da peletização, o teor de carbono fixo, o teor de cinzas, o comprimento e a durabilidade dos pellets. Por outro lado, a inclusão do Pinus aumentou o poder calorífico superior, o teor de voláteis e o diâmetro dos pellets. Os tratamentos F75P25 e o F25P75 foram os pellets de melhor qualidade energética. Com base na norma ISO 17225-2, os pellets produzidos com misturas de Pinus e falhas de pinhão tem qualidade para uso industrial.

Palavras-chave: Araucaria angustifólia; falha de pinhão; Pinus; norma ISO 17225.
\end{abstract}

\begin{abstract}
Use of waste from the production chain of pinion for the production of pellets for energy generation. This work aimed to analyze the quality of pellets produced from different mixtures containing Pinus wood and pinion failure, based on the quality criteria of ISO 17225-2. The materials analyzed in natura and used for the production of the pellets were the failure of the pine tree of Araucaria angustifolia, and the shavings of Pinus spp. The pellets were composed of: $100 \%$ pinion failure (F100); $75 \%$ failure and 25\% Pinus (F75P25); $50 \%$ of each type of biomass (F50P50); 25\% failure and 75\% Pinus (F25P75) and 100\% Pinus (P100). The physical, chemical and energetic properties of the in natura biomass and the physical, mechanical and energetic properties of the pellets produced with the different biomass mixtures were analyzed. The pellets are further classified according to the quality categories of ISO 17225-2. The results showed that the lignin content of the biomass influences the moisture content required in the pelletizing process and that the variations in the properties of the biomass in natura influence the quality of the pellets. The inclusion of Pinus reduced the bulk density of the mixtures before pelletizing, the fixed carbon content, the ash content, the length and the durability of the pellets. On the other hand, the inclusion of Pinus increased the upper calorific value, the volatile content and the diameter of the pellets. The F75P25 and F25P75 treatments were the best energy quality pellets Based on ISO 17225-2, pellets produced from blends of Pinus and pinion failures have quality for industrial use.
\end{abstract}

Keywords: Araucaria angustifólia; sterile scales of araucaria; Pinus; standard ISO 17225.

\section{INTRODUÇÃO}

A espécie Araucaria angustifolia (Bert.) O. Kuntze é o principal componente da Floresta de Araucária. Pertencente à família Araucariaceae é a única espécie de seu gênero com ocorrência natural no Brasil (MANTOVANI et al, 2004). Segundo Backes (1999) a área de ocorrência natural de A. angustifolia ocupava, no 
sul, áreas dos estados do Paraná, Santa Catarina e Rio Grande do Sul. Agrupamentos menores eram encontrados nos estados de São Paulo, Minas Gerais e Espírito Santo. De acordo com Lima; Capobianco (1997) e Guerra et al. (2002), no início do século XX cerca de 35\% da cobertura vegetal dos estados do sul do Brasil estavam representados pela Floresta de Araucária. Atualmente, estima-se que os remanescentes ocupem entre $1 \%$ a $4 \%$ da área original. Em levantamento divulgado pela Indústria Brasileira de Árvores (IBÁ), no ano de 2014, a área ocupada pela A. angustifolia era de apenas 11.122 hectares no Brasil (IBÁ, 2015).

Em relação à Araucária, os produtos e usos mais importantes já estiveram associados à obtenção de madeira, incluindo madeira serrada, usos energéticos (lenha) e fabricação de compensados e celulose. Os galhos e refugos, especialmente o "nó de pinho" servem para lenha e combustível de caldeiras e os pinhões servem de alimento para o homem e animais (GUERRA et al., 2002).

Atualmente, em função das restrições de exploração madeireira os usos mais importantes estão associados ao pinhão (consumo familiar e coleta para comercialização) (VIEIRA DA SILVA E REIS, 2009) e a lenha a partir dos galhos e grimpas para uso nas propriedades agrícolas (GUERRA et al., 2002).

A produção de pinhão é uma atividade de grande importância econômica, que envolve a participação de homens, mulheres e crianças. Pode ser considerada a base da Agricultura Familiar; sendo, em alguns casos, a principal fonte de renda anual das famílias envolvidas nessa atividade (NETO, 2010).

No entanto, o pinhão é apenas um dos componentes do estróbilo feminino da araucária (pinha). Segundo Mantovani et al (2004) em média, 41,8\% do peso fresco dos estróbilos é composto por sementes, $50,7 \%$ por escamas estéreis e não fertilizadas (falhas) e 7,5\% pelo eixo central do estróbilo. As falhas do pinhão, que compõe a maior porção dos estróbilos femininos da araucária, se constituem no principal resíduo gerado durante a separação dos pinhões para consumo ou venda, resultando em grandes volumes em função de sua baixa densidade. Normalmente, este resíduo não é utilizado nos locais onde é gerado, podendo ser deixado no campo para degradar naturalmente, ou queimado a céu aberto pelos produtores de pinhão, para a "limpeza" do local de manufatura do pinhão.

As "falhas" da araucária possuem um potencial para serem utilizadas em práticas de base agroecológica e também para confecção de artesanatos a partir de produtos naturais, podendo ser utilizadas como adubo; matéria seca para composteira; cobertura de solo, para diminuição de capina e para a não utilização de herbicidas; e para tingimento natural de lãs (VIEIRA-DA-SILVA et al., 2011).

Segundo Jacinto et al. (2016), considerando que as regiões de ocorrência natural da araucária possuem clima temperado com invernos rigorosos, mais uma alternativa de uso das falhas de pinhão seria sua aplicação energética, como um combustível alternativo para sistemas de aquecimento residencial ou comercial. Estes autores concluíram ainda que o teor de umidade das falhas in natura foi alto inviabilizando seu uso energético sem prévio tratamento. Com base na composição química imediata e poder calorífico superior, comparativamente à madeira, as falhas de pinhão geram menor quantidade de energia por unidade de massa e maior quantidade de resíduos após a queima, no entanto queimam mais lentamente. A quantidade de lignina e extrativos das falhas de pinhão são maiores que na madeira, contribuindo para a boa ligação interna das partículas na produção de compactados. E finalmente, que a produção de briquetes a partir de falhas de pinhão pode ser uma alternativa viável de uso dos resíduos da cadeia produtiva do pinhão, gerando renda para pequenos produtores rurais.

Neste contexto, a produção de compactados, tanto briquetes como pellets, é uma alternativa muito importante para melhorar a densidade energética de resíduos muito leves, como é o caso das falhas de pinhão. Além disso, os pellets podem ser utilizados para gerar energia em equipamentos pequenos e de simples operação, como em residências, para o aquecimento doméstico. No setor de serviços, são utilizados no aquecimento de água e ambientes em hotéis, academias, por exemplo, e no setor industrial, para a produção de energia térmica de processo ou para a geração de energia elétrica. Nestes dois últimos casos, os pellets são queimados em equipamentos de maior porte, mas que ainda mantém a vantagem de fácil operação.

A produção e o consumo de pellets vêm crescendo tanto no Brasil como no mundo. Segundo Tavares; Tavares (2015), a indústria de pellets no Brasil é recente, tendo um número reduzido de empresas, com produção nacional um pouco superior a 30.000 toneladas/ano, sendo a madeira de Pinus, a matéria-prima mais utilizada para a produção deste energético. O país tem alguns entraves político e técnicos que estão limitando o crescimento da produção de pellets, no entanto possui muitas vantagens comparativas em relação ao outros países produtores e consumidores. Estas vantagens, relacionadas a crescente demanda mundial para este produto energético, torna o Brasil um país com grande potencial produtor de pellets, tanto para consumo interno como para exportação.

Portanto, resolvendo problemas básicos de transporte da matéria prima para a fábrica e do produto já acabado e buscando matérias-primas que dispensem a maior parte do tempo de secagem e tenham, por isso, um 
preço mais competitivo, os estudos indicam que o país teria condições de se beneficiar muito com a participação nesse comércio internacional (TAVARES; TAVARES, 2015).

Assim, estudos que envolvam a análise de novas matérias-primas são fundamentais para o crescimento da produção de pellets no Brasil. Aliado a isso, como os resíduos de Pinus conferem aos pellets produzidos com esta matéria-prima propriedades físicas, mecânicas e energéticas que atendem aos parâmetros de qualidade internacional exigidos pelos mais importantes importadores e consumidores mundiais, os estudos devem também levar em consideração a madeira de Pinus como parâmetro de comparação de qualidade com os outros materiais analisados.

Neste contexto, este trabalho teve como objetivo analisar a qualidade dos pellets produzidos a partir de diferentes misturas contendo madeira de Pinus e falhas de pinhão, com base nos critérios de qualidade da norma ISO $17225-2$.

\section{MATERIAL E MÉTODOS}

Os materiais utilizados foram as escamas estéreis e não fertilizadas (falha do pinhão) obtidas a partir do estróbilo feminino (pinhas) de árvores de Araucaria angustifolia, e a maravalha de Pinus spp fornecida por uma fábrica de portas localizada em Lages, Santa Catarina. As falhas de pinhão foram coletadas no município de Urubici, em Santa Catarina, no mês de junho de 2016, no período de safra do pinhão que compreende os meses de abril a junho na região de ocorrência da espécie. Por se tratar do resíduo da colheita do pinhão, as falhas foram recolhidas em propriedades rurais de agricultores que coletam esta semente para comercialização. As falhas quando não utilizadas são deixadas em pilhas a céu aberto nos locais onde as pinhas (estróbilo feminino) da $A$. angustifolia são abertas para a retirada dos pinhões. Por ser um material de biodegradação lenta, estas pilhas ficam por longo período do solo.

Tanto para falha como para a serragem, em torno de $200 \mathrm{~kg}$ de cada material foi coletado para posterior análise e processamento para a produção dos pellets. Para a caracterização física, química e energética das matérias-primas, as mesmas foram moídas em moinho do tipo Willey e utilizada a fração da biomassa in natura (falhas e a maravalha de Pinus) que passou pela peneira de 40 mesh e ficou retida em peneira de 60 mesh, sendo determinadas as propriedades relacionadas na tabela 1 .

Tabela 1. Propriedade físicas, químicas e energéticas da maravalha de Pinus e das falhas de pinhão utilizadas na produção de pellets.

Table 1. Physical, chemical and energetic properties of Pinus and of the pinion failures used in the production of pellets.

\begin{tabular}{lcc}
\hline Análise & Norma & Repetições \\
\hline Composição química imediata & ASTM 1762 (ASTM, 2007)* \\
Poder calorífico superior e líquido & DIN 51900 (DIN, 2000) \\
& TAPPI T257 cm-02 (TAPPI, 1994); \\
Teor de extrativo totais e teor de lignina & TAPPI T264 cm -97 (TAPPI, 1994); \\
Teor de Umidade & TAPPI T222 om-06 (TAPPI, 2016) \\
Densidade básica & EN 14774 (CEN, 2009) \\
Densidade a Granel & Método hidrostático \\
Granulometria & $* *$ & 3 \\
\hline
\end{tabular}

NOTA: * A determinação do teor de carbono fixo foi realizada por diferença, a partir dos valores de teor de voláteis e teor de cinzas obtidos em Balança Termogravimétrica. ** O método de determinação da densidade a granel foi estereométrico, sendo utilizado para a determinação do volume um Becker de 4,5 litros, preenchido com a biomassa a ser analisada e determinada a massa de ambos em balança de precisão. A densidade foi determinada pela razão entre a massa e o volume das amostras.

Para peletização, a maravalha de Pinus não teve tratamento prévio, enquanto a falha de pinhão passou por moagem e secagem. Foi realizado um teste preliminar de peletização com o Pinus, onde se constatou que a granulometria da maravalha estava adequada ao processo. Assim, a granulometria da maravalha foi considerada como parâmetro para a realização da moagem das falhas.

Para a falha de pinhão foi realizada a moagem inicialmente em moinho com tela de abertura de $5 \mathrm{~mm}$ (F1). Nos testes de peletização feitos com o material nesta granulometria, as misturas com $75 \%$ ou mais de falhas não tiveram boa formação dos pellets, em função da alta proporção de finos (partículas com dimensões inferiores a 3,35 mm), derivada da moagem em peneira com abertura muito pequena. Isso porque o vão entre o rolo compressor e a matriz da peletizadora é de $3 \mathrm{~mm}$. Em função disso, nova moagem foi feita com abertura da peneira de $10 \mathrm{~mm}$ (F2). Assim, para os tratamentos F75P25 e F100 (Tabela 2), foi utilizado o material com

FLORESTA, Curitiba, PR, v. 47, n. 3, p. 353 - 363, jul. / set. 2017

Jacinto, R. C. et al.

ISSN eletrônico 1982-4688

DOI: $10.5380 /$ rf.v47i1.52080 
granulometria obtida na peneira de $10 \mathrm{~mm}$ (F2). Na maravalha de Pinus e na falha de pinhão após moagem foi realizado o teste de granulometria conforme tabela 1.

A peletização foi realizada em uma peletizadora piloto de laboratório com matriz plana de peletização; capacidade máxima de peletização de $400 \mathrm{~kg} / \mathrm{hora}$; variadores de frequência nos: (a) motor elétrico que move a matriz de peletização, (b) no motor do silo de alimentação da biomassa e (c) no motor da esteira vibratória de resfriamento dos pellets; dois conjuntos de sensores de temperatura, um antes da entrada da biomassa na matriz peletizadora e outro na área de peletização da matriz.

Em cada tratamento, a peletizadora foi aquecida até $80^{\circ} \mathrm{C}$. Após alcançar a temperatura desejada foi realizado o processo de peletização. Os parâmetros de peletização foram sendo ajustados até a obtenção de pellets que após o resfriamento mantivessem a compactação e a forma similares ou iguais ao aspecto logo após a saída da matriz de compactação. Enquanto os pellets se desmanchavam ou quebravam, os parâmetros permaneciam sob ajuste.

A tabela 2 mostra a composição dos tratamentos analisados nos testes de peletização, utilizando diferentes misturas contendo falha de pinhão e maravalha de Pinus. Após a realização das misturas, foi realizado o teste de granulometria para verificar possíveis alterações granulométricas em função das composições dos tratamentos.

Tabela 2. Delineamento experimental utilizado para a peletização de diferentes misturas de falha de pinhão e maravalha de Pinus.

Table 2. Experimental design for the pelletization of different mixtures of pine nut failure and pine shavings.

\begin{tabular}{l|cc}
\hline Tratamento & Proporções da mistura (\% do peso total) & PA (kg) \\
\hline F100 & Falha de pinhão 100\% & 75 \\
F75P25 & Falha de pinhão 75\% + Pinus 25\% & 75 \\
F50P50 & Falha de pinhão 50\% + Pinus 50\% & 75 \\
F25P75 & Falha de pinhão 25\% + Pinus 75\% & 75 \\
P100 & Pinus 100\% (Testemunha) & 75 \\
\hline
\end{tabular}

Nota: $\mathrm{PA}=$ Peso do tratamento em kg utilizado no processo de peletização, no teor de umidade em que a peletização foi realizada.

Após a peletização, os pellets foram deixados em câmara climatizadora (umidade relativa do ar de $65 \%$ e temperatura de $22{ }^{\circ} \mathrm{C}$ ) durante um dia para esfriarem, e posteriormente determinadas suas propriedades físicas, mecânicas e energéticas, conforme tabela 3.

Tabela 3. Propriedades analisadas da qualidade dos pellets obtidos nos diferentes tratamentos.

Table 3. Analyzed properties of the quality of the pellets obtained in the different treatments.

\begin{tabular}{lc|c}
\hline Propriedade analisada & Norma & Repetições \\
\hline Dimensões dos pellets e Densidade da unidade & EN 16127 (CEN, 2012) & $100 \mathrm{~g}$ \\
Densidade a Granel & $* *$ & 4 \\
Durabilidade e teor de finos* & EN 15210-1 (CEN, 2010) & 3 \\
Teor de Umidade & EN 14774 (CEN, 2009) & 3 \\
\hline Poder Calorífico Superior & DIN 51900 (DIN, 2000) & 3 \\
Composição química imediata & ASTM 1762 (ASTM, 2007) \\
\hline
\end{tabular}

NOTA: ** O método de determinação da densidade a granel foi estereométrico, sendo utilizado para a determinação do volume um Becker de 4,5 litros, preenchido com os pellets a serem analisados e determinada a massa de ambos em balança de precisão. A densidade foi determinada pela razão entre a massa e o volume das amostras. * Norma modificada. A peneira utilizada foi de $3,35 \mathrm{~mm}$ e não de $3,15 \mathrm{~mm}$ com indicado na norma. O tempo do ensaio foi aumentado para 20minutos com velocidade de $25 \pm 2$ RPM durante 500 voltas, diferente do tempo de 10 minutos com 50 $\pm 2 \mathrm{rpm}$, conforme a norma.

Os valores das propriedades dos pellets obtidos em laboratório foram comparados com os parâmetros existentes na Norma ISO 17225-2 (ISO, 2014).

Os resultados obtidos para cada propriedade analisada foram submetidos à análise de variância e as médias dos tratamentos foram comparadas pelo teste de Scott-Knott a $5 \%$ de probabilidade de erro, utilizando programa Sisvar. 


\section{RESULTADOS}

A caracterização das propriedades físicas, químicas e energéticas dos resíduos, antes do processo de peletização, é apresentada na tabela 4 .

Tabela 4. Propriedades físicas e energéticas das falhas do pinhão e maravalha de Pinus.

Table 4. Physical and energetic properties of pine nut faults and pine wood.

\begin{tabular}{ccc}
\hline & \multicolumn{2}{c}{ Tipo de biomassa } \\
\hline Propriedades & Maravalha de Pinus & Falha do Pinhão \\
\hline Teor de umidade na base úmida $(\%)$ & $14,79 \mathrm{~b}$ & $58,91 \mathrm{a}$ \\
Densidade básica $\left(\mathrm{g} / \mathrm{cm}^{3}\right)$ & $0,223 \mathrm{~b}$ & $0,293 \mathrm{a}$ \\
Densidade a granel $\left(\mathrm{g} / \mathrm{cm}^{3}\right)$ & $0,087 \mathrm{~b}$ & $0,168 \mathrm{a}$ \\
Teor carbono fixo $(\%)$ & $18,91 \mathrm{~b}$ & $24,70 \mathrm{a}$ \\
Teor de voláteis $(\%)$ & $80,63 \mathrm{a}$ & $72,95 \mathrm{~b}$ \\
Teor de cinzas $(\%)$ & $0,46 \mathrm{~b}$ & $2,35 \mathrm{a}$ \\
Poder calorífico superior $(\mathrm{kcal} / \mathrm{kg})$ & $4703 \mathrm{a}$ & $4668 \mathrm{a}$ \\
Poder calorífico líquido $(\mathrm{kcal} / \mathrm{kg})$ & $3643 \mathrm{a}$ & $1432 \mathrm{~b}$ \\
Teor de extrativos totais $(\%)$ & $10,09 \mathrm{a}$ & $7,56 \mathrm{~b}$ \\
Teor de lignina $(\%)$ & $26,01 \mathrm{~b}$ & $41,91 \mathrm{a}$ \\
\hline
\end{tabular}

Nota 1: Letras iguais na linha indicam que não houve diferença significativa entre os tratamentos pelo teste de médias de Scott-Knott a um nível de probabilidade de 0,05 .

A distribuição granulométrica das biomassas antes do processo de peletização e das misturas utilizadas para a produção dos pellets é apresentada na tabela 5 .

Tabela 5. Granulometria das biomassas antes do processo de peletização e das misturas utilizadas na peletização.

Table 5. Granulometry of the biomasses before the pelletizing process and the mixtures used in pelleting.

\begin{tabular}{|c|c|c|c|c|c|c|}
\hline \multirow{2}{*}{\multicolumn{2}{|c|}{ Tipo de biomassa }} & \multicolumn{5}{|c|}{ Distribuição granulométrica (\%) } \\
\hline & & \multirow{2}{*}{$\begin{array}{c}\geq \mathbf{3 1 , 5} \mathbf{~ m m} \\
0,00 \mathrm{~B}\end{array}$} & \multirow{2}{*}{$\begin{array}{c}\geq \mathbf{1 6} \mathbf{~ m m} \\
0,03 \mathrm{~A}\end{array}$} & \multirow{2}{*}{ 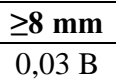 } & \multirow{2}{*}{$\frac{\geq \mathbf{3 , 3 5} \mathbf{~ m m}}{1,63 \mathrm{C}}$} & $<3,35 \mathrm{~mm}$ \\
\hline \multirow{3}{*}{ Biomassa antes da peletização } & F1 & & & & & $98,30 \mathrm{~A}$ \\
\hline & $\mathrm{F} 2$ & $0,00 \mathrm{~B}$ & $0,30 \mathrm{~A}$ & $0,00 \mathrm{~B}$ & $15,97 \mathrm{~A}$ & $83,63 \mathrm{~B}$ \\
\hline & $\mathrm{P}$ & $0,27 \mathrm{~A}$ & $0,47 \mathrm{~A}$ & $6,53 \mathrm{~A}$ & $11,37 \mathrm{~B}$ & $81,40 \mathrm{~B}$ \\
\hline \multirow{5}{*}{ Misturas antes da peletização } & F100 & $0,0 \mathrm{~b}$ & $0,3 \mathrm{a}$ & $0,0 \mathrm{c}$ & $16,0 \mathrm{a}$ & $83,7 \mathrm{c}$ \\
\hline & $\mathrm{F} 75 \mathrm{P} 25$ & $0,0 \mathrm{~b}$ & $0,5 \mathrm{a}$ & $2,0 \mathrm{~b}$ & $17,5 \mathrm{a}$ & $80,0 \mathrm{~d}$ \\
\hline & F50P50 & $0,0 \mathrm{~b}$ & $0,1 \mathrm{a}$ & $1,2 b$ & $10,0 \mathrm{~b}$ & 88,6 a \\
\hline & F25P75 & $0,0 \mathrm{~b}$ & $0,2 \mathrm{a}$ & $7,2 \mathrm{a}$ & $7,5 \mathrm{c}$ & $85,1 \mathrm{~b}$ \\
\hline & $\mathrm{P} 100$ & $0,3 \mathrm{a}$ & $0,5 \mathrm{a}$ & $6,6 \mathrm{a}$ & $11,3 \mathrm{~b}$ & $81,4 \mathrm{~d}$ \\
\hline
\end{tabular}

Nota 1: F1= falha do pinhão moída em peneira de abertura de $5 \mathrm{~mm}$; F2= falha do pinhão moída em peneira com abertura de $10 \mathrm{~mm}$; $\mathrm{P}=$ Pinus; F100 = 100\% de falha de pinhão; F75P25 = 75\% de falha e 25\% de maravalha de Pinus; F50P50 = 50\% de cada tipo de biomassa; F25P75 $=25 \%$ de falha e $75 \%$ de maravalha de Pinus; P100 $=100 \%$ de maravalha de Pinus. Nota 2: Letras iguais na coluna, maiúsculas para a biomassa antes da peletização, e minúsculas para as misturas, indicam que não houve diferença significativa entre os tratamentos pelo teste de médias de Scott-Knott a um nível de probabilidade de 0,05.

Nas tabelas 6 e 7 constam as propriedades avaliadas que determinam a qualidade dos pellets de cada tratamento.

Tabela 6. Propriedades físicas e energéticas dos pellets produzidos a partir de diferentes misturas de falha de pinhão e maravalha de Pinus.

Table 6. Physical and energetic properties of pellets produced from different mixtures of pine nut failure and pine shavings.

\begin{tabular}{c|c|c|c|c|c|c|c|c}
\hline Tratamento & $\begin{array}{c}\text { DG } \\
\mathbf{k g} / \mathbf{m}^{\mathbf{3}}\end{array}$ & $\begin{array}{c}\text { TuAp } \\
(\boldsymbol{\%})\end{array}$ & $\begin{array}{c}\text { TuDp } \\
(\boldsymbol{\%})\end{array}$ & $\begin{array}{c}\text { PCS } \\
(\mathbf{k c a l} / \mathbf{k g})\end{array}$ & $\begin{array}{c}\text { PCL } \\
(\mathbf{k c a l} / \mathbf{k g})\end{array}$ & $\begin{array}{c}\text { CF } \\
(\boldsymbol{\%})\end{array}$ & $\begin{array}{c}\text { TV } \\
(\boldsymbol{\%})\end{array}$ & $\begin{array}{c}\text { TC } \\
(\boldsymbol{\%})\end{array}$ \\
\hline F100 & $0,168 \mathrm{a}$ & $23,87 \mathrm{a}$ & $8,09 \mathrm{c}$ & $4668 \mathrm{~b}$ & $3944 \mathrm{~b}$ & $26,31 \mathrm{a}$ & $71,05 \mathrm{~b}$ & $2,64 \mathrm{c}$ \\
F75P25 & $0,146 \mathrm{~b}$ & $24,60 \mathrm{a}$ & $10,93 \mathrm{a}$ & $4712 \mathrm{~b}$ & $3845 \mathrm{~b}$ & $25,26 \mathrm{a}$ & $73,25 \mathrm{~b}$ & $1,48 \mathrm{~b}$ \\
F50P50 & $0,118 \mathrm{c}$ & $14,00 \mathrm{~b}$ & $8,56 \mathrm{c}$ & $4870 \mathrm{a}$ & $4105 \mathrm{a}$ & $24,76 \mathrm{a}$ & $73,50 \mathrm{~b}$ & $1,72 \mathrm{~b}$ \\
F25P75 & $0,102 \mathrm{~d}$ & $13,18 \mathrm{~b}$ & $7,51 \mathrm{c}$ & $4895 \mathrm{a}$ & $4182 \mathrm{a}$ & $21,76 \mathrm{~b}$ & $77,33 \mathrm{a}$ & $0,91 \mathrm{a}$ \\
P100 & $0,086 \mathrm{e}$ & $13,16 \mathrm{~b}$ & $9,94 \mathrm{~b}$ & $4704 \mathrm{~b}$ & $3944 \mathrm{~b}$ & $22,28 \mathrm{~b}$ & $76,85 \mathrm{a}$ & $0,87 \mathrm{a}$ \\
\hline
\end{tabular}

FLORESTA, Curitiba, PR, v. 47, n. 3, p. 353 - 363, jul. / set. 2017

Jacinto, R. C. et al.

ISSN eletrônico 1982-4688

DOI: $10.5380 /$ rf.v47i1.52080 
Nota 1: DG: densidade a granel das misturas antes da peletização; TUAp= teor de umidade antes da peletização; TUDp= teor de umidade após a peletização; $\mathrm{PCS}=$ Poder Calorífico Superior; PCL=Poder Calorífico Liquido; $\mathrm{CF}=\mathrm{Teor}$ carbono fixo; TV= Teor de Voláteis; TC= Teor de cinzas. Nota 2: Letras iguais na coluna indicam que não houve diferença significativa entre os tratamentos pelo teste de médias de Scott-Knott a um nível de probabilidade de 0,05 .

Tabela 7. Propriedades físicas e mecânicas dos pellets produzidos com diferentes proporções de Pinus e falha de pinhão.

Table 7. Physical and mechanical properties of pellets produced with different proportions of Pinus and pinion failure.

\begin{tabular}{c|cccc|c|c|c}
\hline \multirow{2}{*}{ Tratamento } & $\mathbf{C P}$ & $\boldsymbol{\phi}$ & $\mathbf{D u n}$ & $\mathbf{D u}$ & Finos & DG \\
\cline { 2 - 7 } & $\mathbf{( m m )}$ & $\mathbf{( m m})$ & $\mathbf{( k g / \mathbf { m } ^ { 3 } )}$ & $\mathbf{( \% )}$ & $\mathbf{( \% )}$ & $\mathbf{( \mathbf { k g } / \mathbf { m } ^ { 3 } )}$ \\
\hline F100 & $22,91 \mathrm{~b}$ & $6,03 \mathrm{~d}$ & $1,31 \mathrm{a}$ & $98,84 \mathrm{~b}$ & $1,17 \mathrm{a}$ & $0,658 \mathrm{~b}$ \\
F75P25 & $29,32 \mathrm{a}$ & $6,08 \mathrm{c}$ & $1,21 \mathrm{c}$ & $99,24 \mathrm{a}$ & $0,76 \mathrm{~b}$ & $0,688 \mathrm{a}$ \\
F50P50 & $21,83 \mathrm{c}$ & $6,07 \mathrm{c}$ & $1,25 \mathrm{~b}$ & $98,95 \mathrm{~b}$ & $1,05 \mathrm{a}$ & $0,676 \mathrm{~b}$ \\
F25P75 & $18,56 \mathrm{~d}$ & $6,12 \mathrm{~b}$ & $1,22 \mathrm{c}$ & $98,83 \mathrm{~b}$ & $1,18 \mathrm{a}$ & $0,708 \mathrm{a}$ \\
P100 & $14,99 \mathrm{e}$ & $6,16 \mathrm{a}$ & $1,15 \mathrm{~d}$ & $98,75 \mathrm{~b}$ & $1,27 \mathrm{a}$ & $0,656 \mathrm{~b}$ \\
\hline
\end{tabular}

Nota 1: $\mathrm{CP}=$ comprimento do pellet; $\phi=$ diâmetro do pellet; Dun = densidade da unidade; Du = durabilidade; Finos = teor de finos; DG = densidade a granel. Nota 2: Letras iguais na coluna indicam que não houve diferença significativa entre os tratamentos pelo teste de médias de Scott-Knott a um nível de probabilidade de 0,05

Com base nos parâmetros de qualidade dos pellets analisados, a tabela 8 indica em que categorias de uso cada tratamento se enquadra com base nos critérios de qualidade da Norma ISO 17225-2.

Tabela 8. Especificações técnicas e classificação de uso dos pellets segundo a norma ISO 17225-2, para as categorias de uso A (uso doméstico) e B (setor de serviços) e I (Industrial).

Table 8. Technical specifications and classification of use of pellets according to ISO 17225-2, for use categories A (domestic use) and B (service sector) and use I (Industrial).

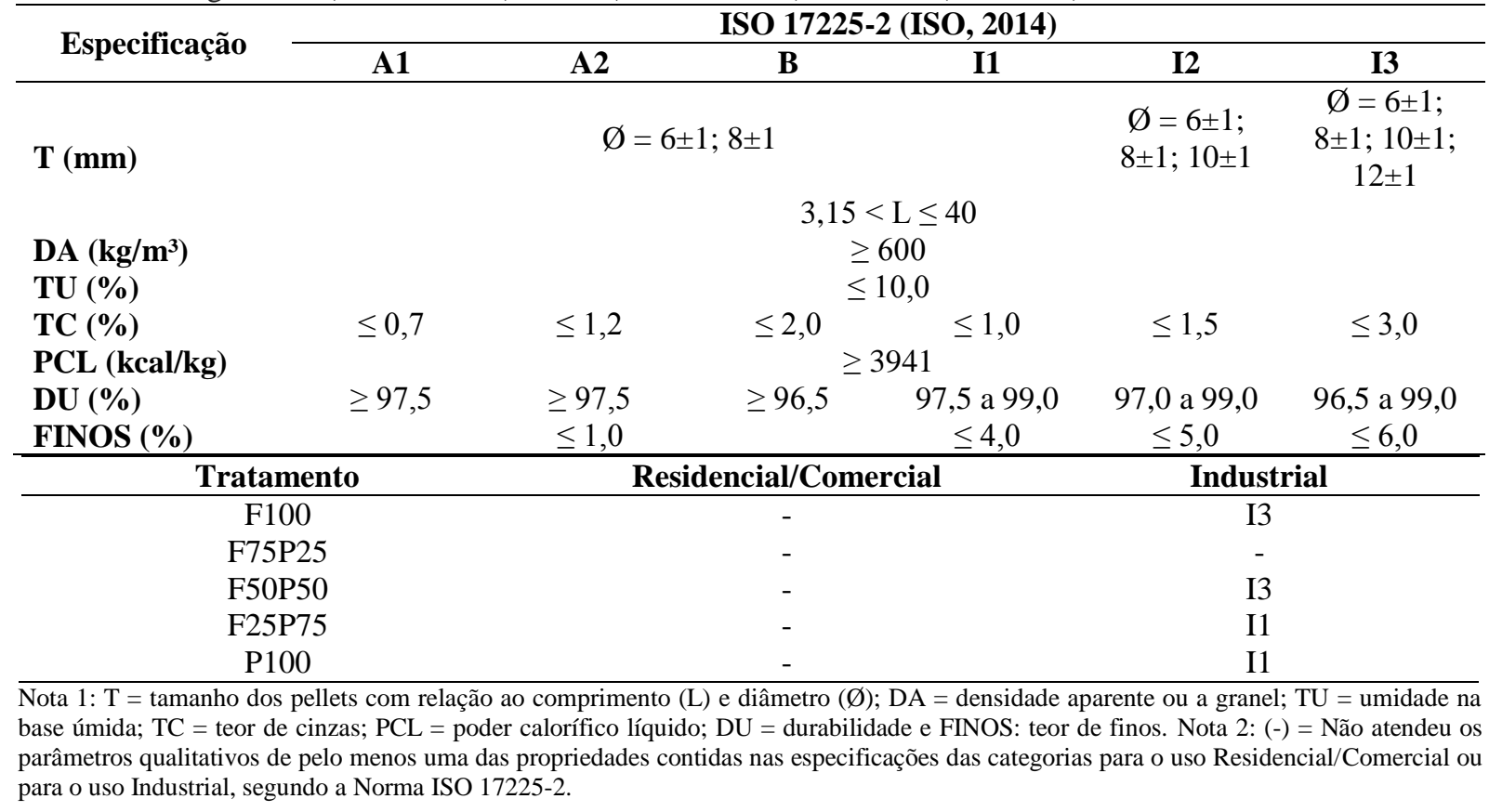

\section{DISCUSSÕES}

\section{Qualidade dos resíduos in natura}

A maravalha de Pinus teve baixo teor de umidade por ser derivada de um processo industrial onde a madeira é previamente seca em estufa para posterior fabricação de portas. As falhas de pinhão apresentaram maior teor de umidade, pois a granulometria e forma deste resíduo, quando armazenado em pilhas ao ar, que é a forma de estocagem mais comum nas propriedades rurais onde o resíduo é gerado, não propiciam a perda da umidade. Assim, este resíduo requer secagem prévia para o processo de peletização (Tabela 4). 
Os resultados de teor de umidade das biomassas analisadas neste trabalho foram similares aos obtidos por Buratto et al. (2015), que encontraram para maravalha de Pinus e para a falha do pinhão, valores de teor de umidade de $14,33 \%$ e $53,86 \%$, respectivamente. Jacinto et al. (2016) determinaram o teor de umidade da falha de pinhão recém colhida e encontraram o valor médio de $61 \%$.

Tanto a densidade básica como a densidade a granel de ambos os materiais analisados apresentaram baixos valores. Além disso, a baixa densidade a granel dos materiais justifica a importância do processo de peletização para o aumento da densidade energética destes resíduos de biomassa, como foi destacado por Zhang (2016).

A falha do pinhão apresentou maior teor de carbono fixo, indicando que comparativamente à maravalha de Pinus teria uma quantidade maior da massa do combustível queimando na forma sólida, tendo combustão mais lenta. Neste trabalho, a porcentagem de carbono fixo para madeira de Pinus foi superior ao encontrado por Peng (2013), que foi de 16,8\%.

O teor de cinzas foi mais alto para as falhas do pinhão. A maravalha de Pinus não possui casca, pois a mesma já foi removida no processamento industrial anterior da madeira, contribuindo para um teor de cinzas muito baixo. Considerando o processo de peletização, são desejados baixos teores de cinzas, sendo limitado a valores inferiores a 3\% mesmo para os pellets das categorias menos restritivas em relação à qualidade, segundo a norma ISO 17225-2 (ISO, 2014) (Tabela 8). Assim, ambas as matérias primas, mesmo para pellets de constituição homogênea de Pinus ou falha, atenderiam aos requisitos da norma, pelo menos para categorias de uso industrial, que são menos restritivas em termos de qualidade.

O poder calorífico superior foi estatisticamente igual para os resíduos. No entanto, quando na determinação do poder calorífico líquido, a falha do pinhão perde significativamente energia, tornado pouco eficiente seu uso energético na forma in natura.

A quantidade de extrativos foi maior para a maravalha de Pinus, enquanto o teor de lignina foi mais alto nas falhas de pinhão. Como destacado por Bradfield e Levi (1984), Kaliyan e Morey (2009), Berghel et al. (2013), Yu et al (2017), o teor de lignina e extrativos presente na biomassa é fundamental para a ligação interna e empacotamento das partículas durante o processo de peletização. Segundo Bradfield e Levi (1984), o conjunto lignina e extrativo promove o aumento da durabilidade dos pellets, pois os polímeros da madeira não cristalinos atuam como um adesivo entre as zonas cristalinas. No entanto, o ganho nesta propriedade foi constatado somente para valores globais de extrativos mais lignina inferiores a $34 \%$.

Neste trabalho, o efeito da lignina no processo de peletização foi sentido durante a compactação dos pellets homogêneos de falha (F100) e na mistura com maior proporção desta biomassa (F75P25). O alto teor de lignina das falhas (Tabela 4) exigiu maior quantidade de umidade na biomassa, até níveis superiores a 23\%, para ocorrer a compactação dos pellets durante a peletização (Tabela 6). Isso porque, maior quantidade de lignina requer maior teor de umidade a uma dada temperatura para ocorrer o processo de transição vítrea deste composto, que é o fenômeno que garante o empacotamento das partículas no compactado.

De forma geral, as falhas de pinhão têm características físicas, químicas e energéticas estatisticamente diferentes em comparação com o Pinus. Assim, as falhas de pinhão têm densidade, teor de carbono fixo, teor de cinzas e teor de lignina maiores que o Pinus, enquanto os teores de voláteis e de extrativos totais foram menores.

\section{Qualidade dos pellets produzidos com diferentes misturas de biomassa residual}

Constatou-se no processo de compactação que a granulometria ideal para peletização em prensa com matriz plana foi de valores próximos ou inferiores a $80 \%$ de partículas inferiores a 3,35 mm, com valores superiores a $5 \%$ de partículas acima de 3,35 $\mathrm{mm}$ (Tabela 5).

A recomendação da norma ISO 17225-2 (ISO, 2014) é de que, para a produção de pellet de biomassa, o material utilizado deve ser triturado de modo que pelo menos $97 \%$ das partículas tenha tamanho inferior a 3,35 mm. Porém, neste trabalho foi observado que uma maior variação e distribuição no tamanho das partículas melhorou o processo de compactação da biomassa na peletizadora. Inclusive, a primeira moagem das falhas (F1), que apresentou $98 \%$ de partículas com menos de 3,35 mm não permitiu a produção de pellets homogêneos de falhas e as misturas com maior porcentagem deste resíduo.

A realização da mistura alterou a granulometria em todos os tratamentos, sendo que somente as partículas com tamanho entre 16 a $31,4 \mathrm{~mm}$ foram semelhantes estatisticamente em todos os tratamentos.

De forma geral, o aumento da proporção de Pinus diminuiu a quantidade de partícula entre 3,35 mm a 7,99 mm e aumentou a quantidade de partículas entre $8 \mathrm{~mm}$ a 15,99 $\mathrm{mm}$. Não alterou a proporção de partículas maiores que 31,5 mm e não houve um comportamento padrão para os finos (menores que 3,35 mm).

Cada tratamento apresentou um comportamento particular, sendo que nenhum ficou próximo do tratamento P100 (com 100\% de Pinus - testemunha). Excetuando a testemunha, a mistura que proporcionou a maior distribuição das partículas dentro das granulometrias analisadas foi o tratamento F75P25.

FLORESTA, Curitiba, PR, v. 47, n. 3, p. 353 - 363, jul. / set. 2017

Jacinto, R. C. et al.

ISSN eletrônico 1982-4688

DOI: $10.5380 /$ rf.v47i1.52080 
A proporção de mistura dos resíduos alterou a densidade a granel dos tratamentos. De forma geral, a inclusão do Pinus na mistura reduziu a densidade a granel dos pellets, sendo que, quanto maior a proporção de Pinus, menor é a densidade a granel da mistura (Tabela 6). A redução da densidade a granel implica no aumento do custo do transporte e requer maior espaço para o armazenamento deste biocombustível, quando comparada a mesma massa de pellets com densidades a granel diferentes.

Para o teor de umidade, os tratamentos contendo maior proporção de falha de pinhão necessitaram de maior teor de umidade para compactação, justamente em função do maior teor de lignina das falhas de pinhão, demonstrando a influência do tipo de biomassa no processo de compactação.

O conteúdo de umidade da biomassa pode afetar a densificação de três maneiras: (a) pela diminuição da temperatura de transição vítrea (TUMULURU et al., 2011); (b) promovendo a formação de pontes sólidas (TUMULURU et al., 2011; MANI et al., 2006) e (c) através do aumento da área de contato de partículas por forças de Van der Waals (MANI et al., 2003). O impacto do teor de umidade é diferente dependendo do tipo de biomassa a ser densificada (TUMULURU et al., 2011) e além disso, um material lignocelulósico excessivamente seco atua como isolamento térmico que impede a transmissão de calor, um elemento-chave no processo de compactação (MANI et al., 2006).

Segundo Niedziółka et al. (2015), a biomassa proveniente de plantas que serão submetidas a compactação, por pressão, deve possuir umidade dentro do intervalo de 8-15\%. Os mesmos autores citam que valores de umidade acima de $15 \%$ podem levar à quebra dos compactados ou à degradação biológica durante o transporte e armazenamento e é a principal causa na diminuição da qualidade dos pellets e do seu poder calorífico. Monteiro et al. (2012) afirma que material bruto com conteúdo de água superior a 15\% é difícil de peletizar.

Neste trabalho foi constatado que quando o teor de lignina é elevado são necessários teores de umidade superiores aos mencionados em literatura durante o processo de peletização. O alto teor de lignina das falhas de pinhão exigiu a adição de água nas misturas com maior proporção desta biomassa para aumentar o teor de umidade até níveis superiores a 23\% (Tabela 6).

Para o teor de umidade, houve diferença estatística entre os tratamentos, com a formação dois grupos, F100 e F75P25, semelhantes entre si, e os demais com maior proporção de Pinus, semelhantes entre si e com menor teor de umidade necessária para peletização. Após a peletização, o teor de umidade dos pellets foi baixo, não havendo relação entre o teor de umidade da biomassa antes do processo de peletização e dos pellets.

Com relação ao poder calorífico superior houve aumento desta propriedade energética com o aumento da proporção de Pinus na mistura, tendo as misturas maiores valores que os tratamentos homogêneos, apesar do tratamento F75P25 ser estatisticamente igual aos tratamentos homogêneos. Como o poder calorífico superior da maravalha de Pinus foi maior que da falha, a inclusão daquela biomassa contribui para o aumento do poder calorífico das misturas dos diferentes tipos de biomassa. Serrano et al. (2011) afirmaram que a maior quantidade de lignina contribui para o aumento do poder calorífico e teor de voláteis em pellets produzidos com diferentes misturas de biomassa, sendo que neste trabalho foi observado o comportamento inverso.

Nos tratamentos contendo falha de pinhão em maior proporção, os teores de carbono fixo foram maiores e semelhantes entre si. Os menores valores foram dos tratamentos F25P75 e P100, com dominância do Pinus na composição dos pellets, demonstrando a influência da matéria-prima na composição química imediata de pellets produzidos a partir da mistura de matérias primas com composição química imediata diferente. O teor de voláteis é inversamente proporcional ao teor de carbono fixo, visto que a somatória destes com o teor de cinzas integraliza a composição imediata do combustível. Portanto, o teor de voláteis teve o mesmo comportamento do carbono fixo.

Para o teor de cinzas, o tratamento homogêneo de falhas de pinhão teve o maior valor, foi diferente de todos os demais tratamentos, demonstrando que a inclusão do Pinus contribuiu para a redução do teor de cinzas dos pellets.

Quanto às dimensões, o comprimento dos pellets aumentou com a inclusão das falhas de pinhão na mistura, enquanto o diâmetro aumentou com a inclusão do Pinus (Tabela 7). Tanto o comprimento quanto o diâmetro são importantes durante a queima dos pellets em queimadores automatizados. Como estes equipamentos são projetados para diâmetros e comprimentos pré-definidos, o aumento do comprimento e do diâmetro dos pellets pode prejudicar o sistema de alimentação das fornalhas entupindo o local de entrada dos pellets no queimador, travando o sistema e requerendo manutenção ou desligamento do equipamento de queima.

A maior densidade da unidade foi obtida para o tratamento F100, a menor para os pellets do tratamento P100, ambos diferentes entre si e com os demais tratamentos. Portanto, as diferenças nas densidades básicas das biomassas in natura influenciaram na densidade dos pellets, sendo que matérias-primas com maior densidade gerarão pellets com maior densidade unitária. $\mathrm{O}$ aumento da densidade unitária representa maior poder calorífico 
volumétrico, ou seja, maior quantidade de energia por unidade de volume, quando for comparado o desempenho energético de pellets com as mesmas dimensões.

A durabilidade foi maior para o tratamento com maior proporção de falha (F75P25) e diferente estatisticamente de todos os demais tratamentos. A inclusão das falhas de pinhão aumentou a durabilidade dos pellets, provavelmente devido ao seu maior teor de lignina como também foi observado por Bradfield e Levi (1984). O teor de finos teve comportamento inverso à durabilidade, com melhor desempenho do tratamento F75P25.

A densidade a granel foi maior para os tratamentos F75P25 e F25P75, que foram estatisticamente iguais, não parecendo haver influência da inclusão do Pinus ou da falha do pinhão no comportamento da densidade a granel dos pellets.

As propriedades que restringiram o enquadramento dos pellets para uso doméstico e industrial foram o teor de cinzas, o teor de finos, o poder calorífico líquido e o teor de umidade dos pellets. Quanto ao teor de cinzas, somente o tratamento homogêneo com falha de pinhão (F100) apresentou valor médio superior ao valor máximo admitido para a categoria menos restritiva para uso no setor de serviços (categoria B). Assim, os pellets homogêneos de falha podem ser utilizados somente para uso industrial (Tabela 8).

Quanto ao teor de finos, nas categorias de uso doméstico e serviço, somente os pellets compostos com $75 \%$ de falhas e $25 \%$ de Pinus, tratamento com melhor qualidade na maioria das propriedades analisadas, atenderam a categoria de uso doméstico (A1) que é mais restritiva. Porém, em função de seu teor de cinzas, seu enquadramento cai para a categoria de uso no setor de serviços (B) e devido ao poder calorífico líquido abaixo do mínimo e teor de umidade superior ao máximo permitido, o tratamento F75P25 fica desclassificado para todos os usos, segundo a norma. No entanto, o teor de umidade, que influencia o poder calorífico líquido, pode ser controlado no processo, fazendo com que este tratamento passe a se enquadrar na categoria de uso no setor de serviços. Todos os demais tratamentos apresentaram teor de finos superior a $1 \%$ não podendo ser usados nas categorias de uso doméstico e serviços.

Quanto a categoria de uso industrial, o teor de cinzas alto das misturas contendo $50 \%$ ou mais de falhas de pinhão e também o tratamento homogêneo com falha de pinhão impediram o enquadramento para uso industrial na categoria mais restritiva (I1). O enquadramento dos tratamentos F100 e F50P50 na categoria I3, menos restritiva também foi em função do teor de cinzas superior ao valor máximo admitido na norma. A desclassificação do tratamento contendo $75 \%$ de falha de pinhão e $25 \%$ de Pinus foi devido ao baixo poder calorífico líquido e alto teor de umidade dos pellets, propriedades estas que podem ser controladas no processo produtivo, melhorando o desempenho deste tratamento.

Assim, segundo a norma ISO 17225-2 (ISO, 2014), os pellets analisados neste estudo poderiam ser utilizados em aplicações industriais. A propriedade de teor de finos pode ser melhorada com alterações na granulometria da biomassa e ajustes no processo de peletização. No entanto, o teor de cinzas alto das falhas do pinhão prejudica a aplicação desta matéria-prima para produção de pellets para usos mais restritivos como o uso doméstico e no setor de serviços.

\section{CONCLUSÃO}

- As diferenças na composição química e nas propriedades físicas e energéticas das falhas de pinhão e da maravalha de Pinus influenciaram no processo de peletização e na qualidade dos pellets obtidos com diferentes misturas destes dois tipos de biomassa.

- A baixa densidade básica e a granel da falha do pinhão e do Pinus tornam o processo de peletização uma alternativa tecnicamente importante para o aumento da densidade energética destes biocombustíveis.

- Independente da mistura utilizada para peletização, a granulometria deve ser constituída de valores próximos ou inferiores a $80 \%$ partículas com dimensões inferiores a $3,35 \mathrm{~mm}$;

- A inclusão do Pinus reduziu a densidade a granel das misturas antes de peletizar, o teor de carbono fixo, o teor de cinzas, o comprimento, a durabilidade dos pellets produzidos com diferentes proporções de misturas de falhas de pinhão e Pinus. Por outro lado, a inclusão do Pinus aumentou o poder calorífico superior, o teor de voláteis e o diâmetro dos pellets;

- Os pellets produzidos a partir de misturas com as duas biomassas tiveram melhor qualidade que os pellets homogêneos de maravalha de Pinus ou de falha de pinhão.

- Considerando de forma conjunta todas as propriedades analisadas, os tratamentos F75P25 e o F25P75 foram as misturas que produziram os pellets de melhor qualidade energética.

- Com base na norma ISO 17225-2, todo os pellets produzidos neste estudo poderiam ser aplicados somente a usos industriais. Nenhuma das misturas analisadas ou os pellets homogêneos atenderam os requisitos para uso doméstico e no setor de serviços.

FLORESTA, Curitiba, PR, v. 47, n. 3, p. 353 - 363, jul. / set. 2017

Jacinto, R. C. et al.

ISSN eletrônico 1982-4688

DOI: $10.5380 /$ rf.v47i1.52080 


\section{REFERÊNCIAS}

AMERICAN SOCIETY FOR TESTING AND MATERIALS, ASTM, D 1762 e 84: Standard Test Method for Chemical Analysis of Wood Charcoal, 2007.

BACKES, A. Condicionamento climático e distribuicão geográfica de Araucaria angustifolia (Bertol.) Kuntze no Brasil: 2. Pesquisas Bot, n. 49, p. 31-51, 1999.

BERGHEL, J.; FRODESON, S.; GRANSTRÖM, K.; RENSTRÖM, R.; STÅHL, M.; NORDGREN, D.; TOMANI, P. The effects of kraft lignin additives on wood fuel pellet quality, energy use and shelf life. Fuel processing technology, v. 112, p. 64-69, 2013.

BRADFIELD, J.; LEVI, M. P. Effect of species and wood to bark ratio on pelleting of southern woods. For. Prod. J., v. 34, n. 1, 1984.

BURATTO, W. G.; COSTA, V. J.; RIBEIRO, C. B.; GUERI, M. V. D. Análise da co-gaseificação de resíduos de biomassa na serra catarinense e avaliação da eficiência ambiental desta tecnologia. Revista Gestão \& Sustentabilidade Ambiental, v. 4, p. 473-481, 2015.

DEUTSCHES INSTITUT FÜR NORMUNG, DIN, DIN 51900: 1e3, Testing of Solid and Liquid Fuels. Determining the Gross Calorific Value of Solid and Liquid Fuels Using the Bomb Calorimeter, and Calculation of Net Calorific Value e Part 1-3. Berlin, 2000.

EUROPEAN COMMITTEE FOR STANDARDIZATION e CEN. EN 14774e3, Determination of moisture content e Part 3: oven dry method. Moisture in general analysis sample. Brussels, 2009.

EUROPEAN COMMITTEE FOR STANDARDIZATION e CEN. EN 15149-1, Solid Biofuels e Determination of Particle Size Distribution e Part 1: Oscillating Screen Method Using Sieve Apertures of $1 \mathrm{Mm}$ and above. Brussels, 2010, p. 13.

EUROPEAN COMMITTEE FOR STANDARDIZATION e CEN. EN 15210-1. Solid Biofuels. Determination of mechanical durability of pellets and briquettes Part 1: Pellets. Brussels, 2010, p. 12.

EUROPEAN COMMITTEE FOR STANDARDIZATION e CEN. EN 16127. Solid Biofuels. Determination of length and diameter of pellets. Brussels, 2012, p. 10.

GUERRA, M. P.; SILVEIRA, V.; REIS, M. S.; SCHNEIDER, L. Exploração, manejo e conservação da araucária (Araucaria angustifolia). In: SIMÕES, L. L.; LINO, C. F.(org.) Sustentável Mata Atlântica: a exploração de seus recursos florestais. São Paulo: Editora SENAC, 2002. p. 85-101

INDUSTRIA BRASILEIRA DE ÁRVORE, Relatório Ibá 2015. Disponível em: http://iba.org/images/shared/iba_2015.pdf. Acesso:20 de junho de 2016.

INTERNATIONAL ORGANIZATION FOR STANDARDIZATION. ISO 17225-2. Solid Biofuels - Fuel Specifications and classes - Part 2: Graded wood péletes. Genebra. 2014.

JACINTO, R. C.; BRAND, M. A.; RIOS, P. D.; DA CUNHA, A. B.; ALLEGRETTI, G. Análise da qualidade energética da falha de pinhão para a produção de briquetes. Scientia Forestalis, v. 44, n. 112, p. 821-829, 2016.

KALIYAN, N.; MOREY, R. V. Factors affecting strength and durability of densified biomass products. Biomass and bioenergy, v. 33, n. 3, p. 337-359, 2009.

LIMA, A. R.; CAPOBIANCO, J. P. R. (coords.). 1997. Mata Atlântica: avanços legais e institucionais para sua conservação. Documentos do ISA n. 004. Instituto Sócio Ambiental, Brasília.

MANI, S.; TABIL, L. G.; SOKHANSANJ, S. An overview of compaction of biomass grand. Powder Handling and Processing, v. 15, n. 2, 2003.

MANI, S.; TABIL, L. G.; SOKHANSANJ, S. Effects of compressive force, particle size and moisture content on mechanical properties of biomass pellets from grasses. Biomass and Bioenergy, v. 30, n. 7, p. 648-654, 2006.

MANTOVANI, A.; MORELLATO, L. P. C.; REIS, M. S. dos. Fenologia reprodutiva e produção de sementes em Araucaria angustifolia (Bert.) O. Kuntze. Revista Brasileira de Botânica, v. 27, n. 4, p. 787-796, 2004.

MONTEIRO, E.; MANTHA, V.; ROUBOA, A. Portuguese pellets market: Analysis of the production and utilization constrains. Energy Policy, v. 42, p. 129-135, 2012. 
NETO, J. F.; NONES, D. L.; DE SOUZA, M. C.; BURIGO, M. C.; PAVELSKI, L. G. Projeto Kayuvá: Valorização do Pinhão na Agricultura Familiar da Serra Catarinense. UDESC em Ação, v. 4, n. 1, 2010.

NIEDZIÓŁKA, I.; SZPRYNGIEL, M.; KACHEL-JAKUBOWSKA, M.; KRASZKIEWICZ, A.; ZAWIŚLAK, K.; SOBCZAK, P.; NADULSKI, R. Assessment of the energetic and mechanical properties of pellets produced from agricultural biomass. Renewable Energy, v. 76, p. 312-317, 2015.

PENG, J. H., BI, X. T., SOKHANSANJ, S., \& LIM, C. J. Torrefaction and densification of different species of softwood residues. Fuel, v. 111, p. 411-421, 2013.

SERRANO, C.; MONEDERO, E.; LAPUERTA, M.; PORTERO, H. Effect of moisture content, particle size and pine addition on quality parameters of barley straw pellets. Fuel Processing Technology, v. 92, n. 3, p. 699-706, 2011.

TAVARES, M.; TAVARES, SRL. Perspectivas para a participação do Brasil no mercado Internacional de pellets. Holos, v. 5, p. 292-306, 2015.

TECHNICAL ASSOCIATION FOR THE WOLDWIDE PULP, PAPER AND CONVERTING INDUSTRY. TAPPI Standard Test Methods. TAPPI 257: Sampling and Preparing Wood for Analysis. Atlanta, 1994.

TECHNICAL ASSOCIATION FOR THE WOLDWIDE PULP, PAPER AND CONVERTING INDUSTRY. TAPPI Standard Test Methods. TAPPI 264: Preparation of Wood for Chemical Analysis (Including Procedures of Removal of Extractive and Determination of Moisture Content). Atlanta, 1994.

TECHNICAL ASSOCIATION FOR THE WOLDWIDE PULP, PAPER AND CONVERTING INDUSTRY. TAPPI Standard Test Methods. TAPPI T222 Om-06: Acid-insoluble Lignin in Wood and Pulp. Atlanta, 2016.

TUMULURU, J. S.; WRIGHT, C. T.; HESS, J. R.; KENNEY, K. L. A review of biomass densification systems to develop uniform feedstock commodities for bioenergy applications. Biofuels Bioproducts and Biorefining, v. 5, n. 6, p. 683-707, 2011.

VIEIRA DA SILVA, C. E.; REIS, M. S. Produção de pinhão na região de Caçador, SC: Aspectos da obtenção e sua importância para comunidades locais. Ciência Florestal, v. 9, n. 4, p. 365-376, 2009.

VIEIRA-DA-SILVA, C.; MIGUEL, L. A.; REIS, M. S. Utilizações alternativas para a "falha", componente da pinha (Araucaria angustifolia), e seu potencial para a agricultura de base agroecológica. Cadernos de Agroecologia, v. 6, n. 2, p. 1-5, 2011.

YU, J.; PATERSON, N.; BLAMEY, J.; MILLAN, M. Cellulose, xylan and lignin interactions during pyrolysis of lignocellulosic biomass. Fuel, v. 191, p. 140-149, 2017.

ZHANG, Q.; ZHANG, P.; PEI, Z.; RYS, M.; WANG, D.; ZHOU, J. Ultrasonic vibration-assisted pelleting of cellulosic biomass for ethanol manufacturing: An investigation on pelleting temperature. Renewable Energy, v. 86, p. 895-908, 2016. 